\title{
SUSTAINABLE DEVELOPMENT - POVERTY IN EUROPE
}

\author{
Sanda CONSTANTIN ${ }^{1}$
}

\begin{abstract}
The paper presents some aspects about poverty in Europe taking also into consideration the new pandemic context. Some indicators linked with the topic were chosen. The indicators refer to people at risk of poverty or social exclusion, severally materially deprived people, unemployment and employment, government debt. The information was analysed by means of statistical indicators. At the end of the paper, a few aspects regarding the impact of the COVID-19 crisis are presented.
\end{abstract}

Key words: people at risk of poverty or social exclusion, severally materially deprived people, employment, debt.

\section{Introduction}

According to the European Commission, "Sustainable development is firmly anchored in the European Treaties and has been at the heart of European policy for a long time. The 2030 Agenda for Sustainable Development and its 17 Sustainable Development Goals (SDGs), adopted by the UN General Assembly in September 2015, have given a new impetus to global efforts for achieving sustainable development. The EU is fully committed to playing an active role in helping to maximise progress towards the Sustainable Development Goals. The indicator set comprises 102 indicators and is structured along the 17 SDGs. For each SDG, it focuses on aspects that are relevant from an EU perspective". One of those relevant aspects is poverty, especially in the context of the COVID-19 crisis.

\section{Methodology}

There was used official information from EUROSTAT database, "Sustainable development in the European Union", monitoring report on progress towards the SDGs in the EU context, 2021 edition. Statistical methods like time series were used in order to analyse the situation of the main aspects connected with poverty aspects.

\footnotetext{
${ }^{1}$ Transilvania University of Braşov, sanda.constantin@unitbv.ro, ORCID ID: 0000-0001-5258-0164
} 


\section{Results}

An important statistical indicator for a sustainable development is "people at risk of poverty or social exclusion".

According to the EUROSTAT "this indicator corresponds to the sum of persons who are: at risk of poverty after social transfers, severely materially deprived or living in households with very low work intensity.

Persons are counted only once even if they are affected by more than one of these phenomena.

Persons are considered to be at risk of poverty after social transfers, if they have an equivalised disposable income below the risk-of-poverty threshold, which is set at $60 \%$ of the national median equivalised disposable income".

This evolution of the indicator during the last ten years at the level of the European Union 27 countries is presented in Figure 1.

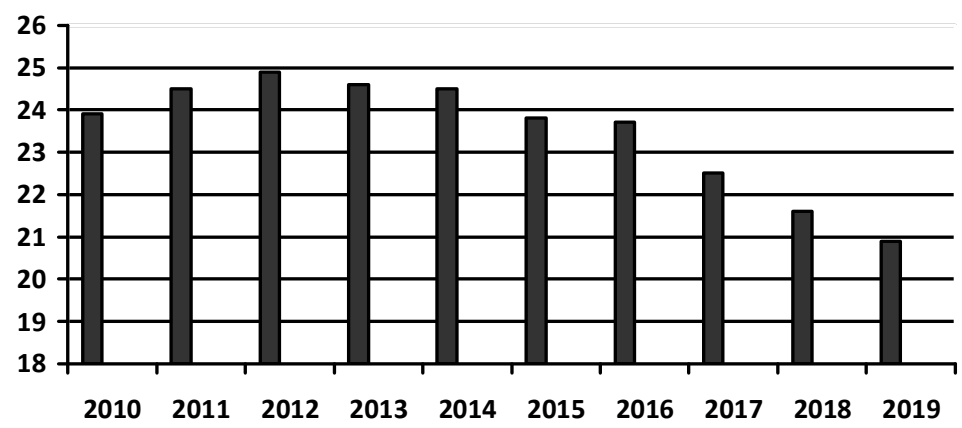

Fig. 1. EU: People at risk of poverty or social exclusion

Data source:

https://ec.europa.eu/eurostat/databrowser/view/sdg_01 10/default/table?lang=en

In the European Union 27 countries during the entire analysed period 2010-2019, the indicator "people at risk of poverty or social exclusion" increased the beginning, until 2014 in comparison with the first year 2010 from $23.9 \%$ to $24.5 \%$, then it started to decrease every year to $20.9 \%$ in 2019.

The highest increase was in 2013 in comparison with the first year 2010 by $0.7 \%$ followed by 2011 and 2014 with an increase by $0.6 \%$.

The lowest levels were registered in the Czech Republic with $12.5 \%$, Slovenia, $14.4 \%$, Finland $15.6 \%$, Norway $16.1 \%$, Slovakia $16.4 \%$ and the Netherlands with $16.5 \%$.

The highest levels were registered in Italy $25.6 \%$, Lithuania $26.3 \%$, Latvia $27.3 \%$, Greece 30\%, Romania 31.2\% and Bulgaria 32.8\%.

On average, each year, the level of people at risk of poverty or social exclusion decreases by $0.33 \%$.

It is worth mentioning that there is no information for the entire European Union for the pandemic period. 
For Romania, the evolution of the indicator during the last eleven years is presented in Figure 2:

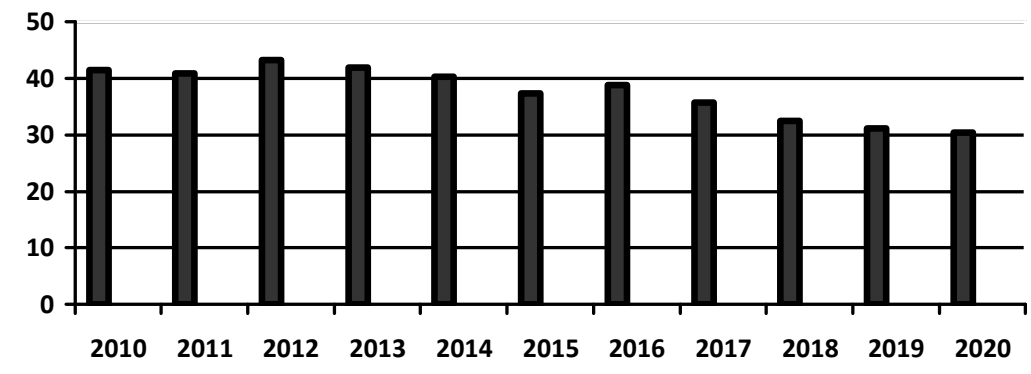

Fig. 2. Romania: People at risk of poverty or social exclusion

In Romania, the indicator for "people at risk of poverty or social exclusion" fluctuates during the analysed period. The indicator decreased at the beginning by $0.6 \%$ in 2011 in comparison with the previous year 2010, then increased in 2012 in comparison with 2011 by $2.3 \%$, then it started to decrease almost every year, but that decrease became slower at the end of the analysed period. On average, every year, the level of the indicator decreased by $1.11 \%$.

Another indicator correlated with poverty is "severely materially deprived people". According to EUROSTAT, "severely materially deprived persons have living conditions severely constrained by a lack of resources, they experience at least 4 out of 9 of the following deprivation items: cannot afford to i) pay rent or utility bills, ii) keep home adequately warm, iii) face unexpected expenses, iv) eat meat, fish or a protein equivalent every second day, v) a week holiday away from home, vi) a car, vii) a washing machine, viii) a colour TV, or ix) a telephone".

The evolution of the indicator during the last ten years at the level of the European Union 27 countries is presented in Figure 3.

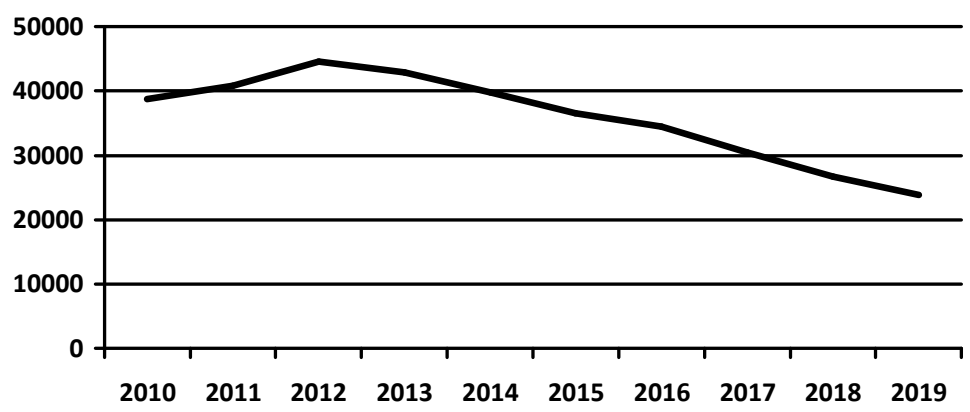

Fig. 3. EU: Severely materially deprived people

Data source:

https://ec.europa.eu/eurostat/databrowser/view/t2020_53/default/table?lang=en 
In the European Union, the number of persons severely materially deprived increased at the beginning of the analysed period until 2014, then started to decrease each year until the last year 2019. Also there is no information about this indicator for the pandemic period. In comparison with the first year 2010, the indicator increased by 5911 thousand persons in 2012, meaning by $15.3 \%$ and by 1122 thousand persons in 2014 , meaning by $2.9 \%$. Starting from 2015, the level of the indicator started to decrease every year by 2200 thousand persons in 2015 in comparison with 2010, meaning by $5.7 \%$, and by 14850 thousand persons, meaning by $38.4 \%$ in 2019 .

From one year to another, the highest increase was in 2012 in comparison with the previous year 2011 by 5911 thousand persons, meaning by $15.3 \%$. The highest decrease was in 2018 in comparison with 2017, by 12001 thousand persons, meaning by $12.2 \%$.

On average, every year the number of persons severely materially deprived decreased by 1650 thousand persons $(5.23 \%)$.

The lowest level of persons severely materially deprived is in Luxembourg (8 thousand persons), Malta (18 thousand persons), Estonia (43 thousand persons) and Slovenia (53 thousand persons.

The highest levels are in Spain (2189 thousand persons), France (2891 thousand persons), Romania (2950 thousand persons) and Italy (4443 thousand persons).

The evolution of the indicator "severely materially deprived people" between 2010 and 2020 in Romania is presented in Figure 4:

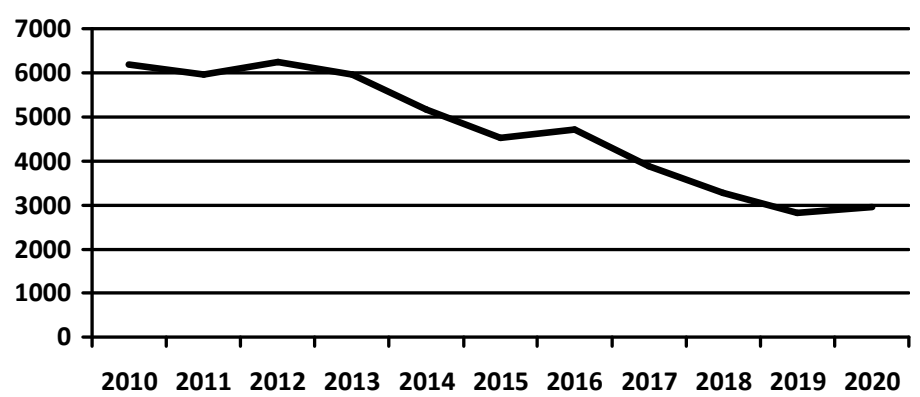

Fig. 4. Romania: Severely materially deprived people

In Romania, the number of persons severely materially deprived decreased almost every year during the entire period 2010-2020 in comparison with the first year 2010, except 2012, when the indicator registered an increase by 61 thousand persons, meaning by 1\%. The highest decrease was in 2019 in comparison with 2010, by 3357 thousand persons, meaning by $54.3 \%$.

From one year to another the number of persons severely materially deprived also decreased constantly with some exceptions. The indicator increased in 2012 in comparison with the previous year 2011 by 280 thousand persons, meaning by $4.6 \%$, in 2016 in comparison with 2015 by 187 thousand persons, meaning by $4.1 \%$ and, unfortunately, in 2020 , in comparison with 2019 , by 121 thousand persons, meaning by $4.3 \%$. 
The pandemic situation has had a huge impact in the European Union, as well as all over the world. As already mentioned, information for this period is missing.

The pandemic situation has required huge responsibility for governments in order to reduce the impact of the COVID 19 crisis. This has led to an increase of governments' debt, as presented in Figure 5:

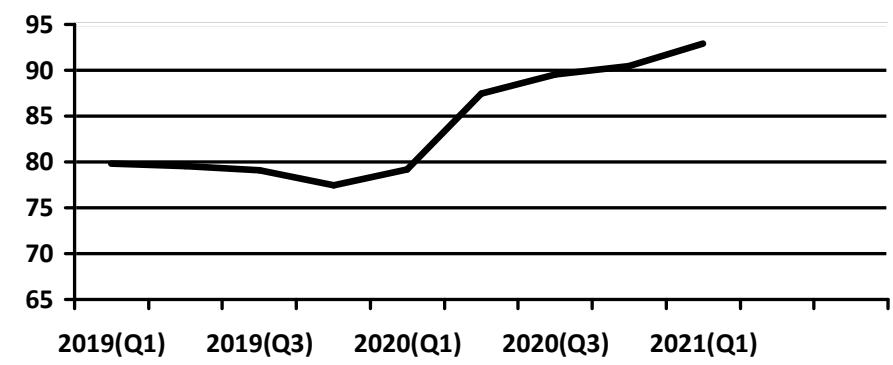

Fig. 5. EU: General government gross debt (quarterly)

Data source:

https://ec.europa.eu/eurostat/databrowser/view/GOV 10Q GGDEBT custom 671204/bookmark/ta ble?lang=en\&bookmarkld=ba0f94c9-3c60-444b-a712-e6ddfdd2f9e5

The government debt increased during the entire year 2020, as well as in the first quarter of 2021. The general government gross debt increased from $79.8 \%$ in the first quarter of 2020 to $92.9 \%$ in the first quarter of 2021.

Also, the COVID-19 crisis has affected the labour market. The evolution of unemployment and employment during this period is presented in Figure 6 and Figure 7:

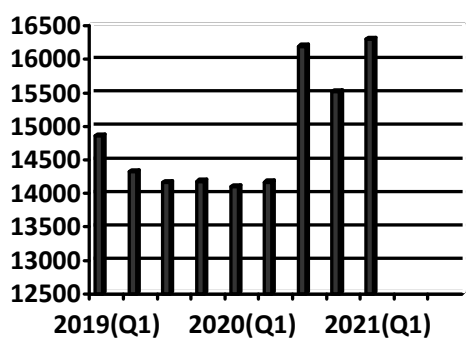

Fig. 6. EU: Unemployment

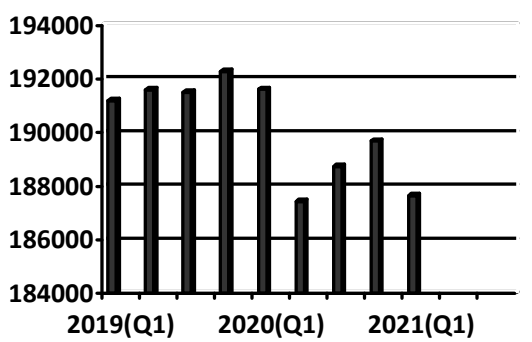

Fig. 7. EU: Employment

Data source: https://ec.europa.eu/eurostat/databrowser/view/UNE RT Q

https://ec.europa.eu/eurostat/databrowser/view/LFSI EMP Q

As it can be observed, the unemployment rate increased in 2020, as well as in the first quarter of 2021. As a result of this situation, employment has decreased over the last period. This situation has a huge impact over the people's incomes and the need for an adequate life. 


\section{Conclusions}

As it can be observed, the evolution of the indicators regarding poverty is a good one, both in the European Union and in Romania. Still, the lack of information for the last period might determine a false image of that important aspect. The reality will be revealed in the future period. The economies of all countries decreased due to the pandemic crisis, so strong measures are necessary. Paolo Gentiloni, commissioner at the European Commission and responsible for Economy and Eurostat said: "Rebuilding a sustainable and resilient Europe also requires substantial financial resources. The Recovery and Resilience Facility offers an unprecedented opportunity to create European flagship areas for investments and reforms with tangible benefits for the economy and citizens across the EU. The six pillars of the Recovery and Resilience Facility are closely aligned with the priorities of the SDGs, ranging from the green transition to smart, sustainable and inclusive growth, as well as including policies for the next generation, such as education and skills".

\section{References}

https://ec.europa.eu/eurostat/web/products-statistical-books/-/KS-03-21-096. Accessed at 21.09 .2021

https://ec.europa.eu/eurostat/databrowser/view/sdg_01_10/default/table?lang=en. Accessed at 22.09.2021

https://ec.europa.eu/eurostat/databrowser/view/t2020_53/default/table?lang=en Accessed at 21.08.2021

https://ec.europa.eu/eurostat/databrowser/view/GOV_10Q_GGDEBT_custom_671204 /bookmark/table?lang=en\&bookmarkld=ba0f94c9-3c60-444b-a712-e6ddfdd2f9e5 Accessed at 25.09.2021

https://ec.europa.eu/eurostat/databrowser/view/LFSI_EMP_Q_custom_672272/book mark/table?lang=en\&bookmarkld=afc5af06-bcf4-4897-8c17e8cf675f2233https://ec.europa.eu/eurostat/databrowser/view/UNE_RT_Q_custom_ 672286/bookmark/table?lang=en\&bookmarkld=14e4e2ba-29f1-44e1-8dffde68cf386d4d. Accessed at 25.08.2021 